\title{
Fabrication of Strontium Bismuth Oxides as Novel Battery-Type Electrode Materials for High-Performance Supercapacitors
}

\author{
Yinghui Han $\mathbb{D}^{1,2}$ Le Li $\mathbb{D}^{1,3}$ Yunpeng Liu $\mathbb{D}^{1,3}$ Xue Li, ${ }^{1,3}$ Xiaohan Qi, ${ }^{1,3}$ and Lili Song ${ }^{1,2}$ \\ ${ }^{1}$ Hebei Key Laboratory of Distributed Energy Storage and Micro-Grid, North China Electric Power University, No. 619 North of \\ Yonghua Street, Baoding 071003, China \\ ${ }^{2}$ School of Mathematics and Physics, North China Electric Power University, No. 619 North of Yonghua Street, \\ Baoding 071003, China \\ ${ }^{3}$ Department of Electric Engineering, North China Electric Power University, No. 619 North of Yonghua Street, \\ Baoding 071003, China
}

Correspondence should be addressed to Yunpeng Liu; liuyunpeng@ncepu.edu.cn

Received 4 July 2018; Accepted 5 August 2018; Published 17 September 2018

Academic Editor: Sheng-Heng Chung

Copyright () 2018 Yinghui Han et al. This is an open access article distributed under the Creative Commons Attribution License, which permits unrestricted use, distribution, and reproduction in any medium, provided the original work is properly cited.

\begin{abstract}
A simple and efficient process method for the preparation of strontium bismuth oxides (SBOs) via an impregnation-calcination method is presented. The synthesized active materials are characterized using X-ray diffraction, scanning electron microscopy, and X-ray photoelectron spectroscopy. The electrochemical performance of the as-synthesized SBO samples is observed to decrease gradually as the strontium content is increased from $25 \%$ to $50 \%$. The SBO sample with a Sr/Bi ratio of $1: 3$ shows the highest specific capacitance of $1228.7 \mathrm{Fg}^{-1}$ (specific capacity of $204.8 \mathrm{mAh} \mathrm{g}^{-1}$ ) at a current density of $1 \mathrm{~A} \mathrm{~g}^{-1}$ and a good cycling stability $(75.1 \%)$ over 3000 charge-discharge cycles. The improved performance of the supercapacitors can be attributed to the unique structural features resulting from the addition of appropriate portions of Sr, which supports high electron conductivity and rapid ion/electron transport within the electrode and at the electrode/electrolyte interface. All the results show that the SBOs have considerable potential for use as high-performance battery-type electrodes in supercapacitors.
\end{abstract}

\section{Introduction}

With a growing concern over serious issues such as global warming and increasing depletion of fossil fuels, researchers have been motivated to work towards improving the performance of the energy storage and conversion devices [1,2]. The supercapacitor, also known as an electrochemical capacitor, is an excellent energy storage device, owing to its fast charge-discharge ability, high power density, and remarkable cycling stability [3].

Energy can be stored in supercapacitors by two different mechanisms: (1) non-Faradaic charge separation in a Helmholtz double layer at the interface between the conductive electrode and electrolyte (electrical double-layer capacitors, EDLCs) and (2) reversible Faradaic redox reactions at or near the electrode surface (pseudocapacitors)
[4-6]. Supercapacitors have a lower energy density than batteries, which may hinder their wide usage [7]. To overcome this disadvantage, new electrode materials with rational nanostructures have been developed in recent years. These materials demonstrate superior electrochemical properties for use in supercapacitors [8]. Carbon-based materials, conducting polymers, and metal oxides are the three basic types of electrode materials [9]. Among them, metal oxides have been extensively investigated because they have a higher energy density than traditional carbon-based materials and a better electrochemical stability than conducting polymers [2]. For example, $\mathrm{NiO}$ [8], $\mathrm{MnO}_{2}$ [10], $\mathrm{Co}_{3} \mathrm{O}_{4}$ [11], and $\mathrm{TiO}_{2}$ [12] exhibit an excellent electrochemical performance, owing to their reversible multielectron redox Faradaic reactions $[13,14]$. However, an electrode using a single metal oxide has drawbacks such as low conductivity and poor 
cycling stability [11]. Coupled metal cations can contribute to improving the metallic conductivity and electrochemical activity [15], which are indispensable for pseudocapacitor applications [16].

Binary metal oxides, such as $\mathrm{NiMn}_{2} \mathrm{O}_{4}$ [13], $\mathrm{NiCo}_{2} \mathrm{O}_{4}$ [17], $\mathrm{MnCo}_{2} \mathrm{O}_{4}$ [18], $\mathrm{NiMoO}_{4}$ [19], and $\mathrm{CuCo}_{2} \mathrm{O}_{4}$ [20], are in high demand as supercapacitor electrode materials. In recent studies, strontium-based bimetal oxides $\left(\mathrm{Sr}_{x} \mathrm{M}_{y} \mathrm{O}_{z}\right.$, where $\mathrm{M}$ is any metal ion, for example, $\mathrm{SrRuO}_{3}$ and $\mathrm{SrTiO}_{3}$ ) have been demonstrated to have excellent metallic properties and show immense potential for supercapacitor applications [21-23]. The preparation of a brownmilleritetype $\mathrm{SrCoO}_{2.5}$ nanostructure with a specific capacitance of $168.5 \mathrm{Fg}^{-1}$ (specific capacity of $28.1 \mathrm{mAh} \mathrm{g}^{-1}$ ) has been reported by Xiao et al. [24]. $\mathrm{SrZrO}_{3}$ nanocrystals were synthesized by Dasa et al. [25]. A $\mathrm{SrZrO}_{3}$ electrode exhibited a high specific capacitance of $23.0 \mathrm{Fg}^{-1}$ (specific capacity of $7.7 \mathrm{mAh} \mathrm{g}^{-1}$ ) at a current density of $1 \mathrm{~mA} \mathrm{~cm}^{-2}$. A specific capacitance of $\sim 270 \mathrm{Fg}^{-1}$ (specific capacity of $90 \mathrm{mAh} \mathrm{g}^{-1}$ ) for a $\mathrm{SrRuO}_{3}$ perovskite electrode in $6 \mathrm{M} \mathrm{KOH}$ has been reported by Wohlfahrt-Mehrens et al. [26]. However, there are limited reports on the use of strontium-based bimetal oxide electrodes in supercapacitors, and it is still a challenge to obtain the desired specific capacity from these electrodes.

The high ionic conductivity [27], superior superconducting behavior [28], small bandgap energy [29], and excellent high-temperature stability [30] of strontium bismuth oxides (SBO) have generated a significant interest in the possibility of their application as electroceramic materials, photocatalysts, superconductors, and fuel cells. To the best of our knowledge, the supercapacitive performance of a bimetal SBO has not been reported. In this work, SBO active materials were successfully synthesized as potential battery-type electrode materials for supercapacitors via a simple and efficient impregnation-calcination method. Their physical and chemical properties were characterized using scanning electron microscopy (SEM) and $\mathrm{X}$-ray diffraction (XRD). Cyclic voltammetry (CV), galvanostatic charge-discharge (GCD) analysis, and electrochemical impedance spectroscopy (EIS) were used for electrochemical characterization in a typical three-electrode system. The electrochemical measurements showed that the SBO-based electrodes possessed excellent capacitive properties and electrochemical stability.

\section{Experimental}

2.1. Material Preparation. All the analytical grade reagents were used as-purchased without further purification. Pure $\mathrm{Bi}_{2} \mathrm{O}_{3}$ was prepared from a $\mathrm{Bi}\left(\mathrm{NO}_{3}\right)_{3} \cdot 5 \mathrm{H}_{2} \mathrm{O}$ precursor using a chemical bath reaction method that was reported in a previous work [31]. The SBO-active material was obtained by an impregnation-calcination method.

$0.761 \mathrm{~g}$ of $\mathrm{Sr}\left(\mathrm{NO}_{3}\right)_{3}$ and $2.5 \mathrm{~g}$ of $\mathrm{Bi}_{2} \mathrm{O}_{3}$ (with a $\mathrm{Sr} / \mathrm{Bi}$ molar ratio of $1: 3$ ) were first dispersed in $10 \mathrm{ml}$ of deionized water under vigorous stirring. This homogeneous solution was treated in an ultrasonic cleaning machine at a frequency of $120 \mathrm{kHz}$ for $10 \mathrm{~h}$ and then kept at $80^{\circ} \mathrm{C}$ under stirring until a viscous gel was formed. After being dried at $10^{\circ} \mathrm{C}$ for $12 \mathrm{~h}$, the dried precursors were finally calcined at $800^{\circ} \mathrm{C}$ for $12 \mathrm{~h}$ in air. When the precipitate cooled to room temperature $\left(25^{\circ} \mathrm{C}\right)$, a yellow powder was obtained, which is denoted as $\mathrm{SBO}-1: 3$. For comparison, composites with different $\mathrm{Sr} / \mathrm{Bi}$ molar ratios $(1: 2$ and $1: 1)$ in the initial reactants were prepared. The corresponding samples are denoted as SBO-1:2 and SBO-1: 1 , respectively.

2.2. Fabrication of the Electrodes. The as-obtained electroactive materials, acetylene black, and polytetrafluoroethylene in a weight ratio of $85: 10: 5$ were ground homogeneously for $2 \mathrm{~h}$ to fabricate the precursor. Then, the mixture was dissolved in ethanol to form a homogeneous paste. The resulting slurry was first spread onto the surface of a nickel foam substrate with a spatula and then dried at $120^{\circ} \mathrm{C}$ overnight to remove the solvent. The nickel foam and the mixture were pressed at $12 \mathrm{MPa}$ by a bead machine to obtain the electrode and then cut into circular disks using a manual slicer of MSK-T10 (with diameter and area of $12 \mathrm{~mm}$ and $1.13 \mathrm{~cm}^{2}$, respectively). The mass loading of the electrodes was approximately $5 \mathrm{mg} \mathrm{cm}^{-2}$.

2.3. Characterization. The crystal structure and phase composition of the samples were analyzed using an X-ray diffractometer (D/MAX-RB, Rigaku, Japan) with a $\mathrm{Cu} \mathrm{K} \alpha$ radiation $(\lambda=1.5418 \AA)$ and recorded in a $2 \theta$ range of $20^{\circ}$ to $70^{\circ}$; the tube voltage and applied current were $40 \mathrm{kV}$ and $40 \mathrm{~mA}$, respectively. The microstructures and morphologies of the samples were investigated using a scanning electron microscope (NanoSEM450, Nova, America) equipped with energy-dispersive X-ray spectroscopy (EDS) equipment. The chemical states of the samples were characterized using X-ray photoelectron spectroscopy (Escalab250, Thermo, America).

The electrochemical measurements were conducted in a standard three-electrode system using a CHI 760E electrochemical workstation (Shanghai $\mathrm{CH}$ Instruments, China) in a $6 \mathrm{M} \mathrm{KOH}$ electrolyte solution. A platinum foil and a saturated calomel electrode (SCE) were employed as the counter and the reference electrodes, respectively. The CV measurements were performed between -0.8 and $-0.2 \mathrm{~V}$ at various scan rates between 5 and $30 \mathrm{mV} \mathrm{s}^{-1}$. The GCD tests were conducted at various current densities between 1 and $5 \mathrm{Ag}^{-1}$. The EIS data were collected by applying an $\mathrm{AC}$ voltage with an amplitude of $5 \mathrm{mV}$ in a frequency range of $10^{-2}$ to $10^{5} \mathrm{~Hz}$.

\section{Results and Discussion}

3.1. Structural and Morphological Characterization. The XRD patterns of the SBO samples with different $\mathrm{Sr} / \mathrm{Bi}$ ratios are shown in Figure 1. Figure 1(a) shows that the strongest diffraction peaks of the SBO-1:3 composite appeared at $2 \theta$ values of $26.1,26.7,28.2,28.9,30.4,45.7$, and $54.6^{\circ}$ from the (101), (012), (009), (104), (015), (110), and (119) crystal planes, respectively. According to the standard diffraction card (PDF number 82-1058), SBO-1:3 was a pure crystalline phase of $\mathrm{Sr}_{0.25} \mathrm{Bi}_{0.75} \mathrm{O}_{1.36}$ with a hexagonal crystal structure 


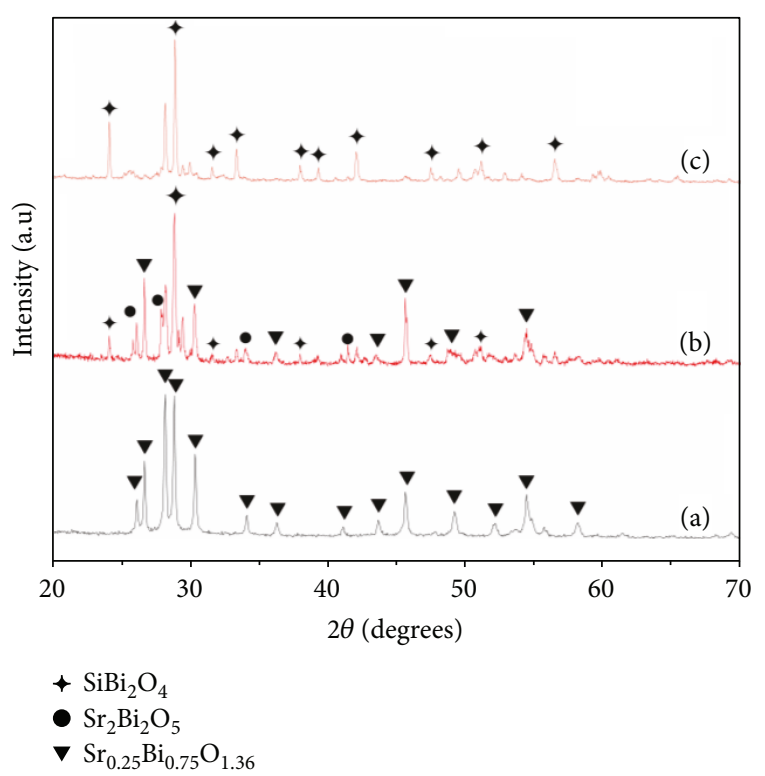

FIgure 1: The X-ray diffraction (XRD) patterns of the SBO samples with different Sr/Bi ratios: (a) SBO-1:3, (b) SBO-1:2, and (c) SBO-1:1.

belonging to the $R-3 \mathrm{~m}$ (166) space group. As the Bi content of the SBO decreased (SBO-1:2), the diffraction peaks in Figure $1(\mathrm{~b})$ show a greater agreement with $\mathrm{Sr}_{0.25} \mathrm{Bi}_{0.75} \mathrm{O}_{1.36}$ (PDF number 82-1058), $\mathrm{Sr}_{2} \mathrm{Bi}_{2} \mathrm{O}_{5}$ (PDF number 89-155 3), and $\mathrm{SrBi}_{2} \mathrm{O}_{4}$ (PDF number 39-1424), indicating that the calcined product changed from single-phase $\mathrm{Sr}_{0.25} \mathrm{Bi}_{0.75} \mathrm{O}_{1.36}$ to a multiphase mixed oxide. For a Sr/Bi molar ratio of $1: 1$ (the SBO-1:1 sample), the diffraction peaks in Figure 1(c) shifted significantly and matched well with the standard pattern of the orthorhombic phase of $\mathrm{Sr}_{2} \mathrm{Bi}_{2} \mathrm{O}_{5}$ (PDF number 89-1553). No peaks for other phases were observed, confirming that pure $\mathrm{Sr}_{2} \mathrm{Bi}_{2} \mathrm{O}_{5}$ was formed.

The morphologies and microstructures of the three samples prepared using different molar ratios are shown in Figure 2. All the micrographs showing particles with coarse surfaces, rough boundaries, and low thickness indicate that they are porous samples consisting of microstructures with a network of open pores. Figure 2(a) shows that the SBO$1: 3$ powder is composed mainly of closely interconnected irregular grains. Owing to their high surface energy and surface tension, these grains with an average diameter of 10$500 \mathrm{~nm}$ form an unconsolidated agglomerate that participates in the calcination process [32]. Many gaps, macropores, and spaces exist between the primary particles, which improve the capacity by increasing the specific surface area for redox reactions. It is noteworthy that nanopores were also observed on the surfaces of these clusters (Figure 2(b)) which provide a path for rapid ion movement at the electrode/electrolyte interface [33]. Surface irregularities including rod-like and bulk shapes can be observed in the SEM image of the SBO-1:2 composite shown in Figure 2(c). As the bismuth content decreases, the boundaries between the particles become clear and the size of the particles increases. It can be observed that the particle surface of SBO-1:1 as shown in Figure 2(d) is smoother and the particle size is larger than that of the other two composites, resulting in smaller pores. Thus, this structure may inhibit further improvement in the electrochemical characteristics. The chemical composition of the particles in the samples SBO-1:3, SBO-1:2, and SBO-1:1 was analyzed using EDS, as shown in the insets of Figures 2(a)-2(d). The atomic ratios of Sr to Bi in the samples were $4.71: 13.97,5.64: 11.66$, and $9.54: 10.32$, which are close to the ideal values of $1: 3,1: 2$, and $1: 1$, respectively. This is in agreement with the XRD results.

To obtain information on the chemical states of the bimetal SBOs, XPS measurements were performed, and the results are shown in Figure 3. The survey spectrum of $\mathrm{Sr}_{0.25} \mathrm{Bi}_{0.75} \mathrm{O}_{1.36}$ (Figure 3(a)) shows the peaks at 132.1, 158.8 , and $530.8 \mathrm{eV}$ which correspond to Sr3d, Bi4f, and $\mathrm{O} 1 \mathrm{~s}$, respectively. Additionally, $\mathrm{C}$ appears in the survey spectrum due to exposure to air. Figure 3(b) shows a highresolution Sr3d spectrum at $130-137 \mathrm{eV}$. The two peaks at 131.88 and $133.48 \mathrm{eV}$, with a separation of $\sim 1.5 \mathrm{eV}$, correspond to $\operatorname{Sr} 3 \mathrm{~d}_{5 / 2}$ and $\operatorname{Sr} 3 \mathrm{~d}_{3 / 2}$, respectively. The +2 oxidation state of Sr is confirmed by the resolved peaks at 132.59 and $134.32 \mathrm{eV} \mathrm{[34].} \mathrm{The} \mathrm{peaks} \mathrm{at} 131.94$ and $133.38 \mathrm{eV}$ correspond to the metallic Sr [35]. The Bi4f spectrum in Figure 3(c) shows multiple splitting with the two main peaks centered at 158.33 and $163.67 \mathrm{eV}$, which correspond to $\mathrm{Bi}_{7 / 2}$ and $\mathrm{Bi}_{5 / 2}$ of $\mathrm{Bi}^{3+}$ [36], respectively. The O1s core-level spectra in Figure 3(d) were fitted with the four components mentioned below. The binding energies of $\mathrm{O} 1(529.08 \mathrm{eV})$ and $\mathrm{O} 2(529.66 \mathrm{eV})$ can be attributed to the oxygen atoms in the $\mathrm{Bi}-\mathrm{O}$ and $\mathrm{Sr}-\mathrm{O}$ layers [37]. The $\mathrm{O} 3$ component at $530.77 \mathrm{eV}$ corresponds to the lattice oxygen of $\mathrm{Sr}_{0.25} \mathrm{Bi}_{0.75} \mathrm{O}_{1.36}$ [38]. At a high binding energy, the $\mathrm{O} 4$ contribution, which appears at $531.62 \mathrm{eV}$, is assigned to low oxygen coordination and is in good agreement with the previously reported energy values [39]. The XPS results confirm the presence of $\mathrm{Sr}^{2+}, \mathrm{Sr}^{0}$, and $\mathrm{Bi}^{3+}$ in $\mathrm{Sr}_{0.25} \mathrm{Bi}_{0.75} \mathrm{O}_{1.36}$.

3.2. Electrochemical Properties. To explore potential application of the SBO in high-performance supercapacitors, we investigated their electrochemical supercapacitive behavior in a $6 \mathrm{M} \mathrm{KOH}$ aqueous electrolyte using a conventional three-electrode configuration with a Pt plate as the counter electrode and an SCE as the reference electrode. Figure 4(a) shows the CV curves of the SBO samples in the potential range of -0.8 to $-0.2 \mathrm{~V}$ at a scan rate of $10 \mathrm{mV} \mathrm{s}^{-1}$. The average specific capacitance $\left(\mathrm{Fg}^{-1}\right)$ and specific capacity values $\left(\mathrm{mAh} \mathrm{g}^{-1}\right)$ were calculated from the CV curves using the following equations $[32,33]$ :

$$
\begin{aligned}
& C=\int \frac{I d t}{\Delta V m v}\left(\mathrm{Fg}^{-1}\right), \\
& C=\int \frac{I d t}{3.6 m v}\left(\mathrm{mAh} \mathrm{g}^{-1}\right),
\end{aligned}
$$

where $I$ is the oxidation or reduction current (A), $\Delta V$ indicates the potential window $(\mathrm{V}), d t$ is the sampling timespan (s), $m$ is the mass of the active electrode material (g), and $\mathrm{v}$ is the potential scan rate $\left(\mathrm{V} \mathrm{s}^{-1}\right)$. The average specific 


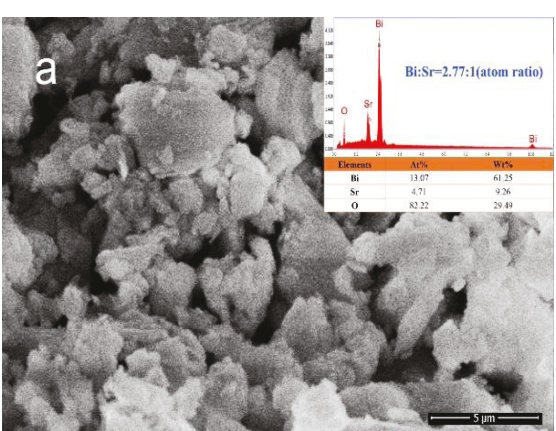

(a)

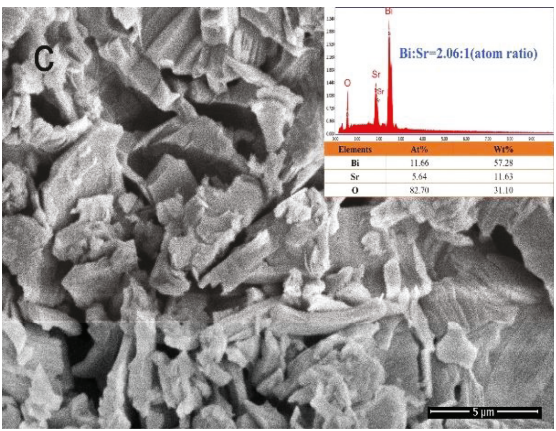

(c)

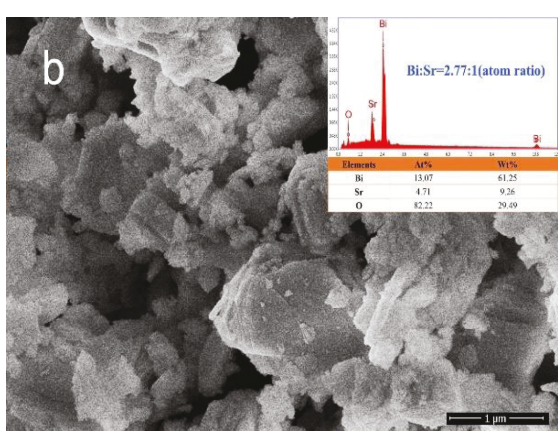

(b)

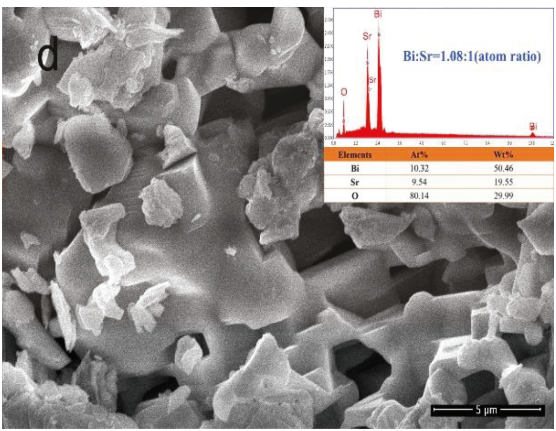

(d)

FIGURE 2: The scanning electron microscopy (SEM) of the three samples prepared using different molar ratios (a) and (b) is SBO-1:3 in different magnifications, (c) SBO-1:2, and (d) SBO-1:1. The insert is the energy-dispersive X-ray spectrometry (EDS) image.

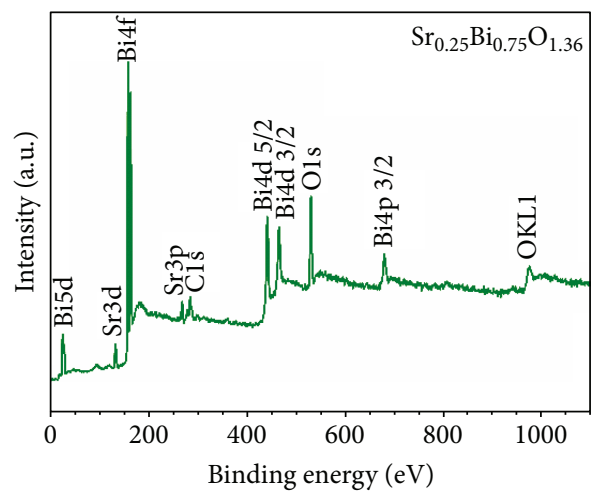

(a)

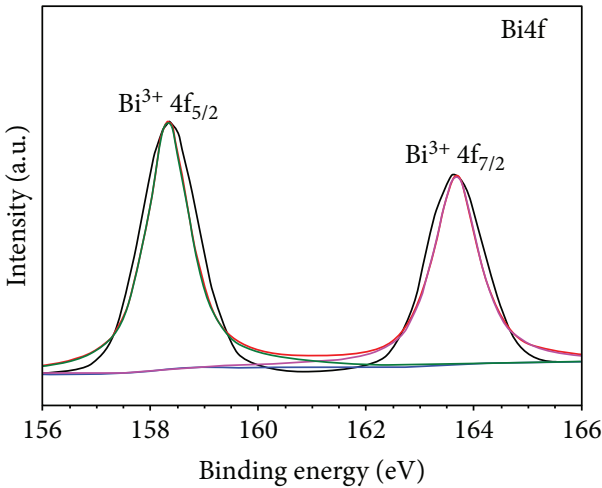

(c)

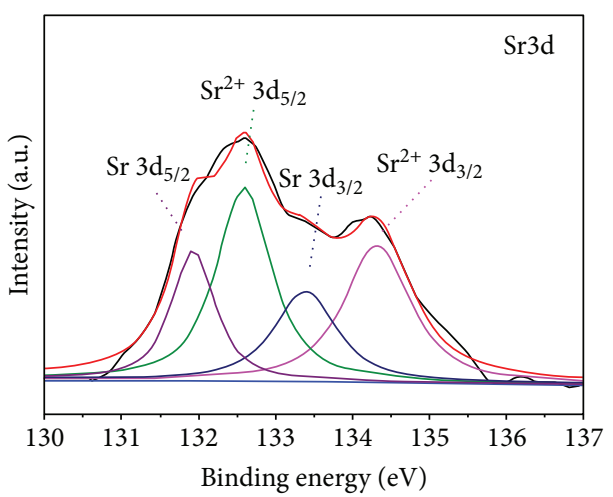

(b)

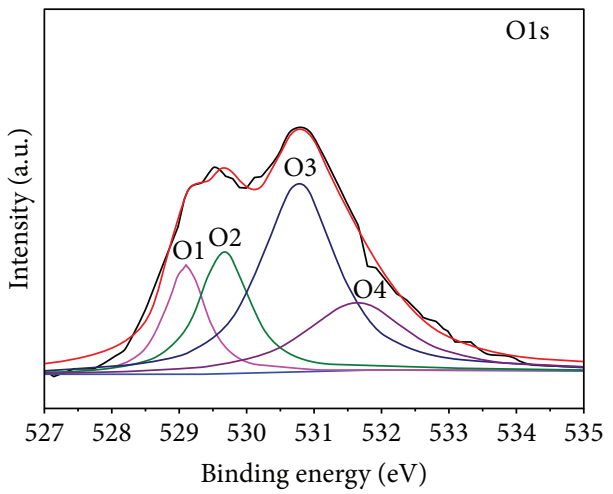

(d)

FIGURE 3: X-ray photoelectron spectroscopy (XPS) spectrum of SBO-1:3 $\left(\mathrm{Sr}_{0.25} \mathrm{Bi}_{0.75} \mathrm{O}_{1.36}\right)$. (a) The full-range XPS survey and the highresolution spectrum of (b) Sr3d, (c) Bi4f, and (d) O1s. 


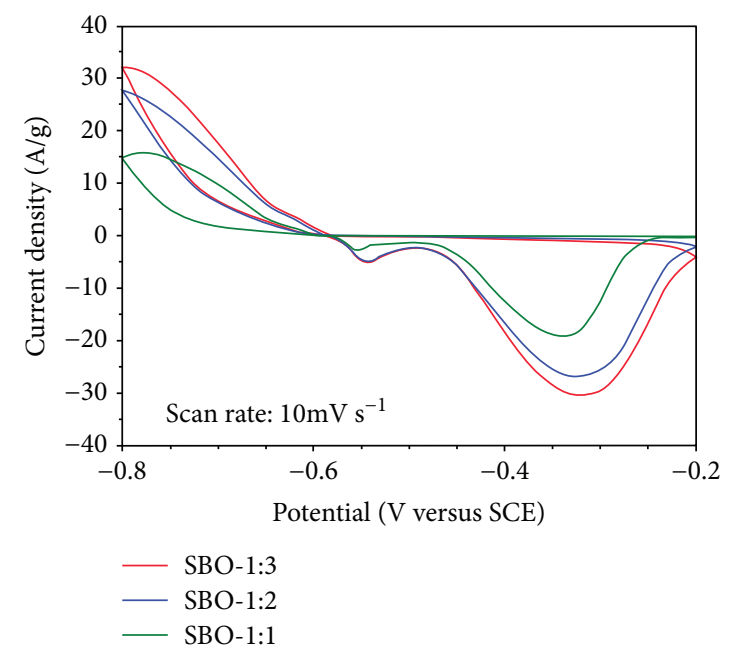

(a)

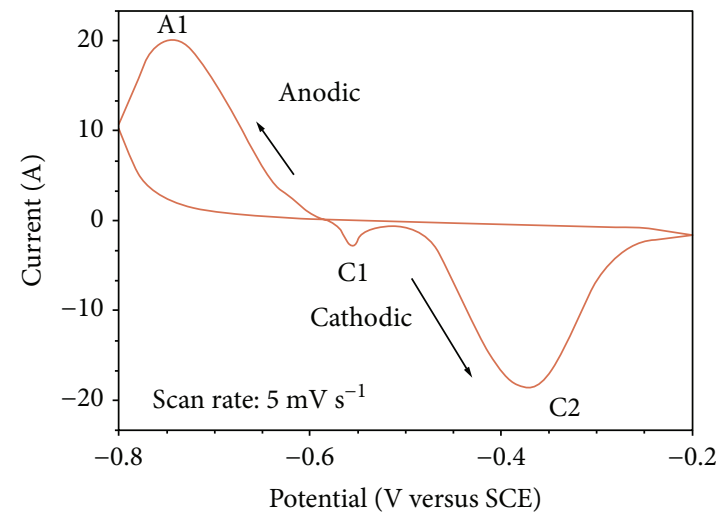

(b)

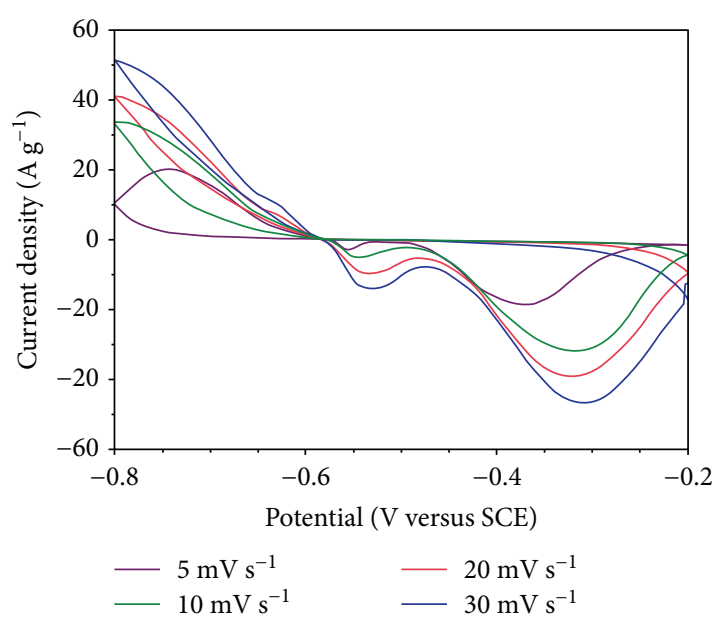

(c)

Figure 4: (a) CV curves of different SBO samples in the potential range of -0.8 to $-0.2 \mathrm{~V}$ at a scan rate of $10 \mathrm{mV} \mathrm{s}^{-1}$, (b) CV curves of SBO$1: 3$ electrodes at scan rate of $5 \mathrm{mV} \mathrm{s}^{-1}$, and (c) CV curves of SBO-1:3 electrodes at scan rate from 5 to $30 \mathrm{mV} \mathrm{s}^{-1}$.

capacitance (specific capacity) of SBO- $1: 3, \mathrm{SBO}-1: 2$, and SBO- $1: 1$ are $559.2,478.8$, and $255.6 \mathrm{Fg}^{-1}(93.2,79.8$, and $42.6 \mathrm{mAh} \mathrm{g}^{-1}$ ), respectively. The value is observed to decrease gradually with an increase in the Sr content.

The CV curves of the SBO consisting two oxidation peaks and a sharp reduction peak are different from those of the EDLCs. The redox peaks are visible in each voltammogram, indicating that the measured capacity arises mainly from the redox mechanism. The SBO-1:3 electrode exhibits a substantially larger capacitive current density than the SBO-1:2 and SBO-1:1 electrodes, demonstrating a superior electrochemical performance. The cyclic voltammogram of the SBO-1:3 electrode is presented in Figure 4(b). The reduction and the oxidation peak potentials of $\mathrm{Sr}_{0.25} \mathrm{Bi}_{0.75} \mathrm{O}_{1.36}$ are similar to those of the $\mathrm{Bi}_{2} \mathrm{O}_{3}$ in the presence of $\mathrm{OH}^{-}$ions [40]. The peaks at potentials of approximately -0.38 and $-0.56 \mathrm{~V}$ during the anodic sweep can be attributed to the transition from $\mathrm{Bi}$ metal to $\mathrm{Bi}(\mathrm{III})$. The peak at a potential of approximately $-0.74 \mathrm{~V}$ during the cathodic sweep is due to the transition of $\mathrm{Bi}(\mathrm{III})$ to metallic $\mathrm{Bi}$. The reaction process can be described as follows $[41,42]$.
During the cathodic sweep,

$$
\begin{aligned}
\mathrm{Sr}_{0.25} \mathrm{Bi}_{0.75} \mathrm{O}_{1.36}- & \rightarrow \mathrm{BiO}_{2}^{-} \\
\mathrm{BiO}_{2}^{-}- & \rightarrow \mathrm{BiO}_{2(\text { ads })}^{-} \\
\mathrm{BiO}_{2(\mathrm{ads})}^{-}+\mathrm{e}^{-}- & \rightarrow \mathrm{BiO}_{2}^{2-}(\text { ads }) \\
2 \mathrm{H}_{2} \mathrm{O}+3 \mathrm{BiO}_{2}^{2-}{ }_{(\text {ads })}- & \rightarrow 2 \mathrm{BiO}_{2(\text { ads })}^{-}+4 \mathrm{OH}^{-}+\mathrm{Bi}_{\text {ads }}^{0}
\end{aligned}
$$

During the anodic sweep,

$$
\begin{aligned}
\mathrm{Bi}_{\mathrm{ads}}^{0}- & \rightarrow \mathrm{Bi}^{+}+\mathrm{e}^{-} \\
2 \mathrm{Bi}^{+}- & \rightarrow \mathrm{Bi}^{3+}+2 \mathrm{Bi}_{\mathrm{ads}}^{0} \\
3 \mathrm{OH}^{-}+\mathrm{Bi}^{3+}- & \rightarrow \mathrm{Bi}(\mathrm{OH})_{3} \\
\mathrm{Bi}(\mathrm{OH})_{3}- & \rightarrow \mathrm{BiOOH}+\mathrm{H}_{2} \mathrm{O}
\end{aligned}
$$

The reaction principles of SBO-1:2 and SBO-1:1 samples are the same as those above. They are not described here. 

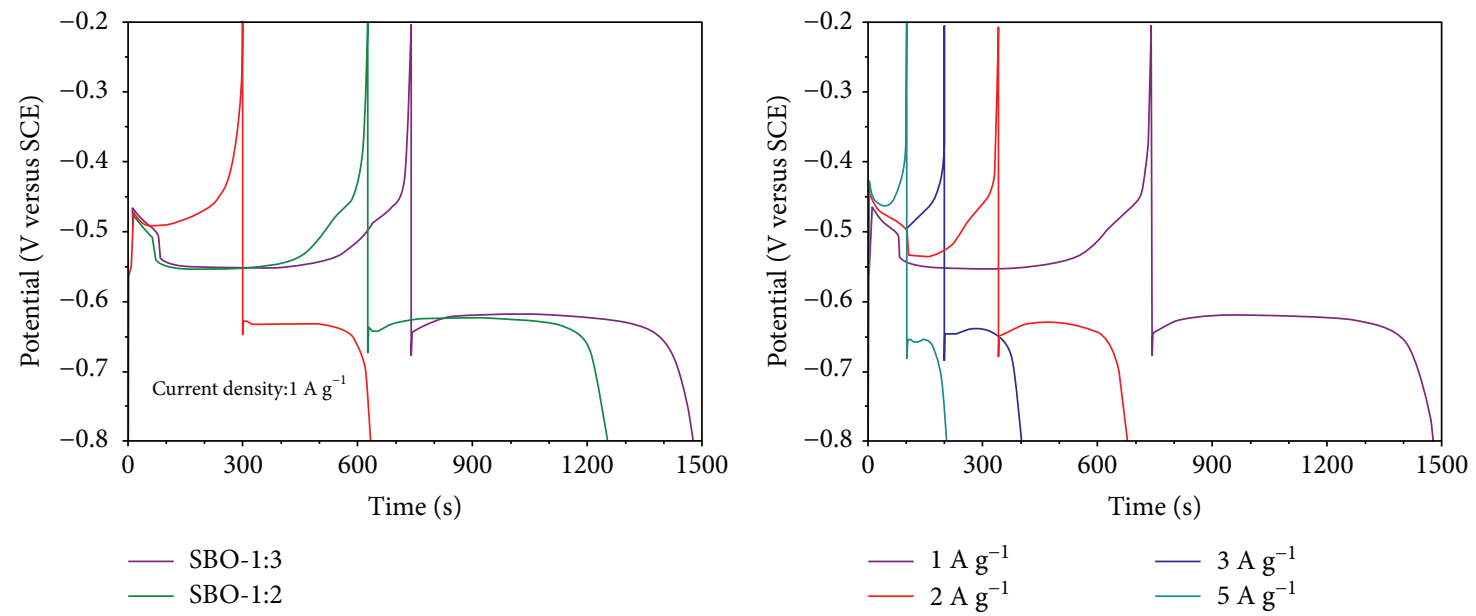

(a)

(b)
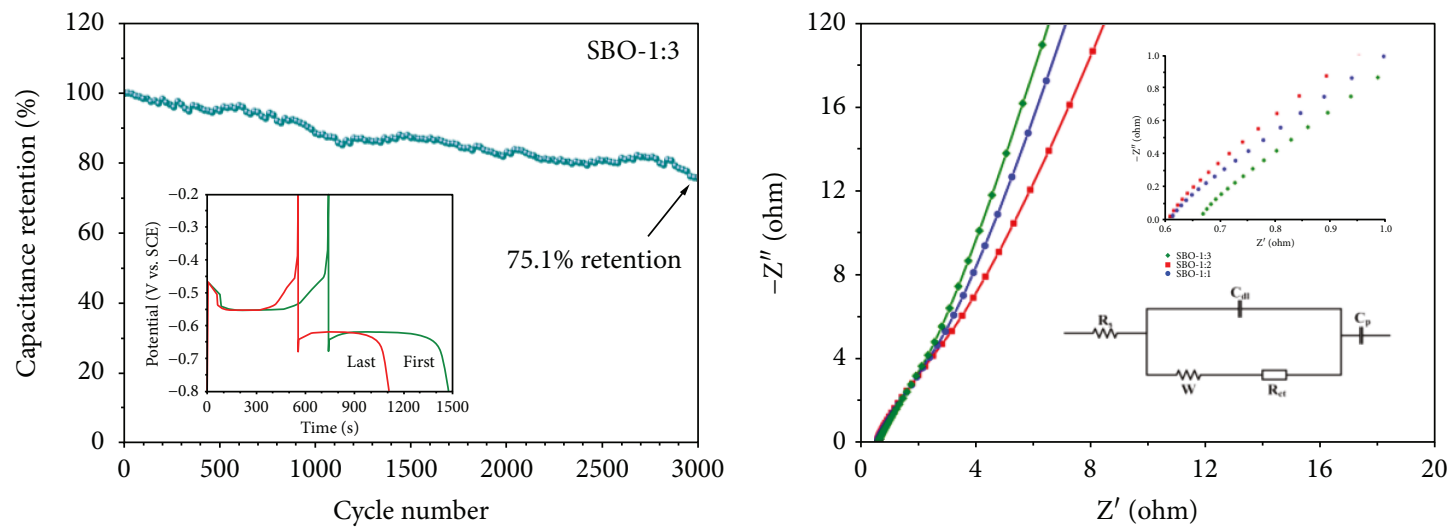

$$
\begin{aligned}
& -\bullet \text { SBO- } 1: 3 \\
& -- \text { SBO-1:2 } \\
& -\bullet-\text { SBO-1:1 }
\end{aligned}
$$

(c)

(d)

FIGURE 5: (a) Charge-discharge curves of different SBO sample electrodes at current density of $1 \mathrm{Ag}^{-1}$, (b) charge-discharge curves of SBO$1: 3$ electrodes at different current density, (c) cycling stability of SBO-1:3 electrodes at the current density of $1 \mathrm{Ag}^{-1}$ (the inset is the first and last charge-discharge cycles), and (d) Nyquist diagrams of the SBO-1:3, SBO-1:2, and SBO-1:1 electrodes at frequencies ranging from $0.01 \mathrm{~Hz}$ to $100 \mathrm{kHz}$ (the insets are the fitting circuit (below) and magnification of the high-frequency area (above)).

Fundamental investigations showed that the combination of $\mathrm{Bi}$ and $\mathrm{Sr}$ in an appropriate proportion yielded a considerable number of oxygen vacancies for pseudocapacitive charge storage. As the oxygen vacancies can contribute to the bulk structure through the mechanism of oxygen intercalation, the observed redox reaction associated with the pseudocapacitive storage in a Bi-based metal oxide is attributed to the direct intercalation of oxygen ions transferred by the oxygen vacancies $[43,44]$. During calcination, oxygen vacancies are comparable with the level of $\mathrm{Sr}$ doping. This results in oxygen vacancies in $\mathrm{Sr}_{0.25} \mathrm{Bi}_{0.75} \mathrm{O}_{1.36}$ (SBO-1:3), where strontium appears in two valence states, $\mathrm{Sr}(0)$ and $\mathrm{Sr}(\mathrm{II})$, according to the XPS results described earlier. No oxygen vacancies were revealed in the analysis of the chemical formula and the valence states of $\mathrm{Sr}_{2} \mathrm{Bi}_{2} \mathrm{O}_{5}$ (SBO-1:1). The electrochemical performance of SBO-1:3 was better than that of SBO-1:1. As an intermediate between SBO-1:3 and SBO-1:1, the capacity of SBO-1:2 was also an intermediate value, which was calculated using the appropriate capacitance formula. The effect on the capacitive properties and electrochemical reaction mechanism of $\mathrm{Sr}^{0}$ in the samples were discussed here. First, Sr has only one oxidation state and was not involved in the redox reactions and thus would not contribute to the pseudocapacitance $[45,46]$. Compared with SBO-1:1, without any different redox peaks could be observed of SBO$1: 3$ and SBO-1:2 in the same potential window through CV. Second, a higher capacitance could be calculated with a higher $\mathrm{Sr}^{0}$ content in samples. We speculate that $\mathrm{Sr}^{0}$ can improve the electronic conductivity and provide a rapid and reversible mass transfer and charge transport. The existence of $\mathrm{Sr}^{0}$ not only decreases the surface resistance of SBO electrode but also increases the probability of the proton transfer [47]. A faster ion/electron migration might be accomplished owing to the close contact through $\mathrm{Sr}^{0}$.

The CV curves of the SBO-1:3 electrode at various scan rates from 5 to $30 \mathrm{mV} \mathrm{s}^{-1}$ in the potential range of -0.8 to 
$-0.2 \mathrm{~V}$ are shown in Figure $4(\mathrm{c})$. As the scan rate increases, the peak current increases in a nonnegligible manner. The shape of the curves is almost retained, and the discrepancies among the three redox peaks also become more noticeable as a result of the inadequate redox process at a rapid scan rate $[48,49]$. The calculated capacitances and capacities are 567.6, 559.2, 394.2, and $340.8 \mathrm{Fg}^{-1}$ (94.6, 93.2, 65.7, and $56.8 \mathrm{mAh} \mathrm{g}^{-1}$ ) at scan rates of $5,10,20$, and $30 \mathrm{mV} \mathrm{s}^{-1}$, respectively. The capacitance decreases as the scan rate increases. This decrease in the capacitance can be ascribed to the diffusion of the ions from the electrolyte into almost all the available pores of the electrode at a low scan rate, leading to a complete insertion reaction [5].

GCD measurements are significant in the analysis and prediction of the performance of electrode materials under practical operating conditions [50]. The charge-discharge cycling behavior of the three SBO electrode samples at a rate of $1 \mathrm{~A} \mathrm{~g}^{-1}$ in the potential range between -0.8 and $-0.2 \mathrm{~V}$ is shown in Figure 5(a). These curves have asymmetric shapes, suggesting that the capacity characteristics of the three SBO samples are not a characteristic of EDLCs. Two discharge plateaus are observed in the three discharge curves, which agree with the result of the CV test. These curves resemble each other quite closely owing to similar changes in the valence state of bismuth $\left[\mathrm{Bi}^{0} \rightarrow \mathrm{Bi}(\mathrm{III}) \rightarrow \mathrm{Bi}^{0}\right]$ during the charge and discharge processes. However, different intermediates were produced in the reversible Faradaic reactions, resulting in different voltage plateaus in the three samples. The specific capacitance $\left(\mathrm{Fg}^{-1}\right)$ and the specific capacity $\left(\mathrm{mAh} \mathrm{g}^{-1}\right)$ of the electrode materials are calculated from the discharge time using the following equations:

$$
\begin{aligned}
& C=\frac{I t}{m \Delta V}\left(\mathrm{Fg}^{-1}\right), \\
& C=\int \frac{I d t}{3.6 m v}\left(\mathrm{mAh} \mathrm{g}^{-1}\right),
\end{aligned}
$$

where $I$ is the discharge current (A), $t$ is the discharge time (s), $\triangle V$ indicates the potential window (V), and $m$ is the mass of active material ( $\mathrm{g}$ ). The specific capacitances and specific capacities calculated from the discharge curves were 1228.7, 1042.2, and 556.2 $\mathrm{Fg}^{-1}$ (204.8, 173.7, and $92.7 \mathrm{mAh} \mathrm{g}^{-1}$ ) for the SBO-1:3, SBO-1:2, and SBO-1: 1 electrodes, respectively. Moreover, these values are consistent with the order indicated by the CV curves. The specific capacitance of the SBO-1:3 electrode is considerably larger than that of the SBO-1:2 and SBO-1:1 electrodes. The remarkable capacitive behavior of SBO-1:3 is attributed to the introduction of oxygen vacancies, which greatly improve the free-electron concentration and thus increase the electron mobility and enhance the rate of redox reactions [51]. Additionally, it is found that sample SBO-1:2 (containing $\mathrm{Sr}_{0.25} \mathrm{Bi}_{0.75} \mathrm{O}_{1.36}, \mathrm{Sr} / \mathrm{Bi}$ ratio of $1: 2$ ) possesses a low abundance of oxygen vacancies, whereas SBO-1:1 (Sr/Bi ratio of $1: 1)$ has no oxygen vacancies. Oxygen intercalation and electron motion may be blocked, owing to the shortage of oxygen vacancies. Therefore, the specific capacitance decreases with increasing $\mathrm{Sr}$ content in the mentioned range
[43]. The charge-discharge curves of the SBO-1:3 electrode at different current densities to evaluate its rate performance are shown in Figure 5(b). The specific capacitance and capacity of SBO-1:3, at a current density of $1 \mathrm{Ag}^{-1}$, are calculated to be $1228.7 \mathrm{~F} \mathrm{~g}^{-1}$ and $204.8 \mathrm{mAh} \mathrm{g}^{-1}$. At a higher current density of $5 \mathrm{Ag}^{-1}$, the specific capacitance of SBO-1:3 is $512.4 \mathrm{~F} \mathrm{~g}^{-1}$ (85.4 $\mathrm{mAh} \mathrm{g}^{-1}$ of specific capacity).

The long-term cyclic stability of supercapacitors is another critical parameter in practical applications. The supercapacitors should work steadily and safely, which demand minimal changes in the specific capacitance of the electrode materials [15]. The relationship between the specific capacitance and the cycling number of the SBO-1:3 material is shown in Figure 5(c). The specific capacitance of SBO-1:3 is $1228.7 \mathrm{~F} \mathrm{~g}^{-1}$ (204.8 $\mathrm{mAh} \mathrm{g}^{-1}$ of specific capacity) at the first cycle, and it decreases gradually as the number of cycles increases. Within 500 cycles, the capacitance was lost up to $95.1 \%$; however, even up to 1500 cycles, the capacitance was retained up to $87.5 \%$. Its capacitance retention ratio is $75.1 \%$ after 3000 cycles. The first and the last (3000th cycle) charge-discharge curves are shown in the inset of Figure 5(c), demonstrating that SBO-1:3 retains a good charge-discharge performance. All the results indicate that SBO-1:3 shows excellent electrochemical stability.

EIS measurements were performed to determine the resistance of the three SBO electrode materials. The Nyquist diagrams of the SBO- $1: 3$, SBO- $1: 2$, and SBO- $1: 1$ electrodes at frequencies ranging from $0.01 \mathrm{~Hz}$ to $100 \mathrm{kHz}$ with an amplitude of $5 \mathrm{mV}$ are shown in Figure 5(d). The impedance plot was fitted using the ZSimpWin software, and the fitting circuit is shown in the inset of Figure 5(d). The Nyquist spectra are generally expected to exhibit a semicircle in the high-frequency region and a straight line in the low-frequency region [41]. In the fitting circuit, $R_{\mathrm{s}}, R_{\mathrm{ct}}$, $C_{\mathrm{dl}}, W$, and $C_{\mathrm{p}}$ are the solution resistance, charge transfer resistance, electric double-layer capacitance, Warburg resistance, and pseudocapacitive element, respectively. The intercepts in the high-frequency region give the values of $R_{\mathrm{s}}$, which are $0.69,0.64$, and $0.68 \Omega$ for SBO- $1: 3$, SBO- $1: 2$, and SBO- $1: 1$, respectively. The $R_{\mathrm{s}}$ values represent a combination of the ionic and electronic resistance, the intrinsic resistance of the electrodes, and the diffusive and contact resistance at the electrode/current collector interface [20]. The semicircle in the high-frequency region is related to the charge transfer resistance $\left(R_{\mathrm{ct}}\right)$ at the electrode/electrolyte interface, which is due to the Faradaic redox reaction of the electrode [41]. The $R_{\mathrm{ct}}$ values of SBO-1:3, SBO-1:2, and SBO- $1: 1$ are $0.23,0.72$, and $0.98 \Omega$, respectively. A lower $R_{\mathrm{ct}}$ value suggests that the Faradaic reaction proceeds more easily and has high reversibility. Thus, SBO-1:3 exhibits the most enhanced supercapacitor performance. The electrochemical active surface area of SBO-1:3 is calculated to be $25.98 \mathrm{~cm}^{2}$. A more vertical line in the low-frequency region indicates that the supercapacitor behaves more like an ideal capacitor [49]. The phase angles for the Nyquist spectra of the SBO samples are higher than $45^{\circ}$. This suggests that the SBO samples exhibit a notable capacitive behavior. The high capacity, low resistance, and long cycle life demonstrate that 
the SBO-active materials (especially SBO-1) are promising electrode materials for supercapacitor applications.

\section{Conclusions}

Three bimetal SBOs with different $\mathrm{Sr} / \mathrm{Bi}$ molar ratios were successfully synthesized via an impregnation-calcination method. The electrodes exhibited reversible charge-discharge behavior and comparable specific capacity values owing to their enhanced electronic conductivity and ion diffusion at the electrode/electrolyte interface. Among the electrodes, the highest specific capacitance $1228.7 \mathrm{Fg}^{-1}\left(204.8 \mathrm{mAh} \mathrm{g}^{-1}\right.$ of specific capacity) at a constant discharge current density of $1 \mathrm{Ag}^{-1}$ and good cycling stability (75.1\%) over 3000 charge-discharge cycles was exhibited by the SBO-1:3 sample with an $\mathrm{Sr} / \mathrm{Bi}$ ratio of $1: 3$. An excellent frequency response for all the SBO samples was revealed by the EIS analyses. All these results indicate that the SBO may be promising materials for electrochemical capacitors.

\section{Data Availability}

The data used to support the findings of this study are available from the corresponding author upon request.

\section{Conflicts of Interest}

The authors declare that they have no conflicts of interest.

\section{Authors' Contributions}

Le $\mathrm{Li}$ was responsible for the experiment, total article structure design, and writing; Yinghui Han and Yunpeng Liu contributed to the article revision and the funding support; Xue Li, Xiaohan Qi, and Lili Song provided lots of comments in the process of revision. Yinghui Han and Le Li contributed equally to this work.

\section{Acknowledgments}

This work is supported by the Fundamental Research Funds for the Central Universities of China (no. 2018QN073 and no. 2015ZZD3) and Hebei Electric Power Science Research Institute Science and Technology Project (no. 14214503D).

\section{References}

[1] S. K. Vijaya and R. Kalai Selvan, "Fabrication of flexible fiber supercapacitor using covalently grafted $\mathrm{CoFe}_{2} \mathrm{O}_{4} /$ reduced graphene oxide/polyaniline and its electrochemical performances," Electrochimica Acta, vol. 213, pp. 469-481, 2016.

[2] Z. Xueqiang, X. Cheng, and Q. Zhang, "Nanostructured energy materials for electrochemical energy conversion and storage: a review," Journal of Energy Chemistry, vol. 25, no. 6, pp. 967984, 2016

[3] K. V. Sankar and R. K. Selvan, "The ternary $\mathrm{MnFe}_{2} \mathrm{O}_{4}$ /graphene/polyaniline hybrid composite as negative electrode for supercapacitors," Journal of Power Sources, vol. 275, pp. 399407, 2015.
[4] A. Pramanik, S. Maiti, M. Sreemany, and S. Mahanty, "Carbon doped $\mathrm{MnCo}_{2} \mathrm{~S}_{4}$ microcubes grown on $\mathrm{Ni}$ foam as high energy density faradaic electrode," Electrochimica Acta, vol. 213, pp. 672-679, 2016.

[5] Y. Zou, Q. Wang, C. Xiang et al., "One-pot synthesis of ternary polypyrrole-Prussian-blue-graphene-oxide hybrid composite as electrode material for high-performance supercapacitors," Electrochimica Acta, vol. 188, pp. 126-134, 2016.

[6] L. Wang, Y. Han, X. Feng, J. Zhou, P. Qi, and B. Wang, "Metal-organic frameworks for energy storage: batteries and supercapacitors," Coordination Chemistry Reviews, vol. 307, Part 2, pp. 361-381, 2016.

[7] A. K. Mondal, H. Liu, Z.-F. Li, and G. Wang, "Multiwall carbon nanotube-nickel cobalt oxide hybrid structure as high performance electrodes for supercapacitors and lithium ion batteries," Electrochimica Acta, vol. 190, pp. 346-353, 2016.

[8] S. M. Moniruzzaman, C. Y. Yue, K. Ghosh, and R. K. Jena, "Review on advances in porous nanostructured nickel oxides and their composite electrodes for high-performance supercapacitors," Journal of Power Sources, vol. 308, pp. 121-140, 2016.

[9] A. M. Abioye and F. N. Ani, "Recent development in the production of activated carbon electrodes from agricultural waste biomass for supercapacitors: a review," Renewable and Sustainable Energy Reviews, vol. 52, pp. 1282-1293, 2015.

[10] N. Li, X. Zhu, C. Zhang, L. Lai, R. Jiang, and J. Zhu, "Controllable synthesis of different microstructured $\mathrm{MnO}_{2}$ by a facile hydrothermal method for supercapacitors," Journal of Alloys and Compounds, vol. 692, pp. 26-33, 2017.

[11] X. Sun, Z. Jiang, C. Li et al., "Facile synthesis of $\mathrm{Co}_{3} \mathrm{O}_{4}$ with different morphologies loaded on amine modified graphene and their application in supercapacitors," Journal of Alloys and Compounds, vol. 685, pp. 507-517, 2016.

[12] A. Lamberti and C. F. Pirri, "TiO ${ }_{2}$ nanotube array as biocompatible electrode in view of implantable supercapacitors," Journal of Energy Storage, vol. 8, pp. 193-197, 2016.

[13] H. Wei, J. Wang, L. Yu, Y. Zhang, D. Hou, and T. Li, "Facile synthesis of $\mathrm{NiMn}_{2} \mathrm{O}_{4}$ nanosheet arrays grown on nickel foam as novel electrode materials for high-performance supercapacitors," Ceramics International, vol. 42, no. 13, pp. 1496314969, 2016.

[14] G. Zhu, J. Yang, Y. Liu et al., "Porous Fe-Mn-O nanocomposites: synthesis and supercapacitor electrode application," Progress in Natural Science-Materials International, vol. 26, no. 3, pp. 264-270, 2016.

[15] H. Wan, L. Lin, P. Lu et al., "Hollow spiny shell of porous Ni-Mn oxides: a facile synthesis route and their application as electrode in supercapacitors," Journal of Power Sources, vol. 286, pp. 66-72, 2015.

[16] Y. Zhang, Z. Shi, L. Liu, Y. Gao, and J. Liu, "High conductive architecture: bimetal oxide with metallic properties @ bimetal hydroxide for high-performance pseudocapacitor," Electrochimica Acta, vol. 231, pp. 487-494, 2017.

[17] S. Sun, S. Li, W. Shen et al., "Fabrication of hollow $\mathrm{NiCo}_{2} \mathrm{O}_{4}$ nanoparticle/graphene composite for supercapacitor electrode," Materials Letters, vol. 182, pp. 23-26, 2016.

[18] K. N. Hui, K. S. Hui, T. Zikang, V. V. Jadhav, and Q. X. Xia, "Hierarchical chestnut-like $\mathrm{MnCo}_{2} \mathrm{O}_{4}$ nanoneedles grown on nickel foam as binder-free electrode for high energy density 
asymmetric supercapacitors," Journal of Power Sources, vol. 330, pp. 195-203, 2016.

[19] Y. Li, J. Jian, L. Xiao et al., "Synthesis of $\mathrm{NiMoO}_{4}$ nanosheets on graphene sheets as advanced supercapacitor electrode materials," Materials Letters, vol. 184, pp. 21-24, 2016.

[20] S. Vijayakumar, S.-H. Lee, and K.-S. Ryu, "Hierarchical $\mathrm{CuCO}_{2} \mathrm{O}_{4}$ nanobelts as a supercapacitor electrode with high areal and specific capacitance," Electrochimica Acta, vol. 182, pp. 979-986, 2015.

[21] X. W. Wang, Q. Q. Zhu, X. Wang, H. C. Zhang, J. J. Zhang, and L. F. Wang, "Structural and electrochemical properties of $\mathrm{La}_{0.85} \mathrm{Sr}_{0.15} \mathrm{MnO}_{3}$ powder as an electrode material for supercapacitor," Journal of Alloys and Compounds, vol. 675, pp. 195200, 2016.

[22] K. Ahmad, A. Mohammad, P. Mathur, and S. M. Mobin, "Preparation of $\mathrm{SrTiO}_{3}$ perovskite decorated rGO and electrochemical detection of nitroaromatics," Electrochimica Acta, vol. 215, pp. 435-446, 2016.

[23] T.-S. Hyun, H.-G. Kim, and I.-D. Kim, "Facile synthesis and electrochemical properties of conducting $\mathrm{SrRuO}_{3}-\mathrm{RuO}_{2} \mathrm{com}$ posite nanofibre mats," Journal of Power Sources, vol. 195, no. 5, pp. 1522-1528, 2010.

[24] F. Xiao, X. Zhang, F. Hu, and J. Zhang, "Preparation and electrochemical capacitance of Brown-Millerite $\mathrm{SrCoO}_{2.5}$ as electrode materials for supercapacitor," Materials Chemistry and Physics, vol. 94, no. 2-3, pp. 221-225, 2005.

[25] R. Dasa, K. J. K. Guptaa, A. Nayakb, and U. C. Ghosha, "Preparation, characterization and dielectric, ac conductivity with electrochemical behavior of strontium zirconate," Advanced Materials Letters, vol. 7, no. 8, pp. 646-651, 2016.

[26] M. Wohlfahrt-Mehrens, J. Schenk, P. M. Wilde, E. Abdelmula, P. Axmann, and J. Garche, "New materials for supercapacitors," Journal of Power Sources, vol. 105, no. 2, pp. 182-188, 2002.

[27] F. X. Zhang, B. Manoun, S. K. Saxena, and C. S. Zha, "Structural behavior of $\mathrm{Sr}_{2} \mathrm{Bi}_{2} \mathrm{O}_{5}$ at high pressures," Journal of Solid State Chemistry, vol. 179, no. 2, pp. 544-550, 2006.

[28] Y. Obukuro, S. Matsushima, K. Obata, M. Arai, and K. Kobayashi, "Improved calculation of band gap of $\mathrm{Sr}_{2} \mathrm{Bi}_{2} \mathrm{O}_{5}$ crystal using modified Becke-Johnson exchange potential," Journal of Physics and Chemistry of Solids, vol. 75, no. 3, pp. 427-432, 2014.

[29] Y. Obukuro, H. Nakamura, K. Obata, S. Matsushima, M. Arai, and K. Kobayashi, "First-principles study on electronic structure of $\mathrm{Sr}_{2} \mathrm{Bi}_{2} \mathrm{O}_{5}$ crystal," Journal of Physics and Chemistry of Solids, vol. 72, no. 12, pp. 1477-1481, 2011.

[30] B. Hallstedt, D. Risold, and L. J. Gauckler, "Thermodynamic assessment of the bismuth-strontium-oxygen oxide system," Journal of the American Ceramic Society, vol. 80, no. 5, pp. 1085-1094, 2005.

[31] P. Hajra, S. Shyamal, H. Mandal, P. Fageria, S. Pande, and C. Bhattacharya, "Photocatalytic activity of $\mathrm{Bi}_{2} \mathrm{O}_{3}$ nanocrystalline semiconductor developed via chemical-bath synthesis," Electrochimica Acta, vol. 123, pp. 494-500, 2014.

[32] M. Shanmugavadivel, V. Violet Dhayabaran, and M. Subramanian, "Nanosized $\mathrm{BaMnO}_{3}$ as high performance supercapacitor electrode material: fabrication and characterization," Materials Letters, vol. 181, pp. 335-339, 2016.

[33] X. Li and B. Wei, "Supercapacitors based on nanostructured carbon," Nano Energy, vol. 2, no. 2, pp. 159-173, 2013.

[34] M. Li, H. Liu, H. Zhu, H. Gao, S. Zhang, and T. Chen, "Kinetics and mechanism of $\mathrm{Sr}$ (II) adsorption by $\mathrm{Al}-\mathrm{Fe}_{2} \mathrm{O}_{3}$ : evidence from XPS analysis," Journal of Molecular Liquids, vol. 233, no. 5, pp. 364-369, 2017.

[35] P. A. W. Van Der Heide, "Systematic X-ray photoelectron spectroscopic study of $\mathrm{La}_{1-\mathrm{X}} \mathrm{Sr}_{\mathrm{x}}$-based perovskite-type oxides," Surface and Interface Analysis, vol. 33, no. 5, pp. 414-425, 2002.

[36] B. Chen, Y. Zhao, D. P. Feng et al., "XPS studies of high$T_{c}$ superconducting $\mathrm{Bi}_{2} \mathrm{Sr}_{2} \mathrm{Ca}\left(\mathrm{Cu}_{1-\mathrm{y}} \mathrm{Fe}_{\mathrm{y}}\right)_{2} \mathrm{O}_{x}$ single crystals," Physica C: Superconductivity, vol. 328, no. 3-4, pp. 145151, 1999.

[37] M. Nagoshi, Y. Fukuda, N. Sanada, Y. Syono, A. TokiwaYamamoto, and M. Tachiki, "O1s core levels of Bi-Sr-Ca$\mathrm{Cu}-\mathrm{O}$ superconductors studied by X-ray photoelectron spectroscopy," Journal of Electron Spectroscopy and Related Phenomena, vol. 61, no. 3-4, pp. 309-322, 1993.

[38] Y. Obukuro, S. Matsushima, K. Obata et al., "Effects of La doping on structural, optical, electronic properties of $\mathrm{Sr}_{2} \mathrm{Bi}_{2} \mathrm{O}_{5}$ photocatalyst," Journal of Alloys and Compounds, vol. 658, pp. 139-146, 2016.

[39] X. Qi, W. Zheng, G. He, T. Tian, D. Naixu, and L. Wang, " $\mathrm{NiCo}_{2} \mathrm{O}_{4}$ hollow microspheres with tunable numbers and thickness of shell for supercapacitors," Chemical Engineering Journal, vol. 309, pp. 426-434, 2017.

[40] S. X. Wang, C. C. Jin, and W. J. Qian, " $\mathrm{Bi}_{2} \mathrm{O}_{3}$ with activated carbon composite as a supercapacitor electrode," Journal of Alloys and Compounds, vol. 615, pp. 12-17, 2014.

[41] Y. C. Zhang, H. Yang, W. P. Wang et al., "A promising supercapacitor electrode material of $\mathrm{CuBi}_{2} \mathrm{O}_{4}$ hierarchical microspheres synthesized via a coprecipitation route," Journal of Alloys and Compounds, vol. 684, pp. 707-713, 2016.

[42] A. A. Ensafi, N. Ahmadi, and B. Rezaei, "Electrochemical preparation of $\mathrm{CuBi}_{2} \mathrm{O}_{4}$ nanoparticles on nanoporous stainless steel as a binder-free supercapacitor electrode," Journal of Alloys and Compounds, vol. 652, pp. 39-47, 2015.

[43] Y. Cao, B. Lin, Y. Sun, H. Yang, and X. Zhang, "Sr-doped lanthanum nickelate nanofibers for high energy density supercapacitors," Electrochimica Acta, vol. 174, pp. 41-50, 2015.

[44] T. Zhai, S. Xie, M. Yu et al., "Oxygen vacancies enhancing capacitive properties of $\mathrm{Mno}_{2}$ nanorods for wearable asymmetric supercapacitors," Nano Energy, vol. 8, pp. 255-263, 2014.

[45] T. Adinaveen, J. Judith Vijaya, M. Amal Raj, P. Iyyappa Rajan, L. John Kennedy, and N. Clament Sagaya Selvam, "Hierarchically arranged strontium oxide nanospheres-impregnated carbon cloth for high performance supercapacitor electrodes," Journal of Electroanalytical Chemistry, vol. 799, pp. 222-227, 2017.

[46] H. Liu, K. H. Ho, Y. Hu et al., "Doping cobalt hydroxide nanowires for better supercapacitor performance," Acta Materialia, vol. 84, pp. 20-28, 2015.

[47] G. Durai, P. Kuppusami, and J. Theerthagiri, "Microstructural and supercapacitive properties of reactive magnetron cosputtered $\mathrm{Mo}_{3} \mathrm{~N}_{2}$ electrodes: effects of $\mathrm{Cu}$ doping," Materials Letters, vol. 220, pp. 201-204, 2018.

[48] L. Li, P. Gao, S. Gai et al., "Ultra small and highly dispersed $\mathrm{Fe}_{3} \mathrm{O}_{4}$ nanoparticles anchored on reduced graphene for supercapacitor application," Electrochimica Acta, vol. 190, pp. 566573, 2016.

[49] Y. Xu, L. Wang, P. Cao, C. Cai, F. Yanbao, and X. Ma, "Mesoporous composite nickel cobalt oxide/graphene oxide synthesized via a template-assistant co-precipitation route 
as electrode material for supercapacitors," Journal of Power Sources, vol. 306, pp. 742-752, 2016.

[50] Q. Wu, M. Chen, S. Wang, X. Zhang, L. Huan, and G. Diao, "Preparation of sandwich-like ternary hierarchical nanosheets manganese dioxide/polyaniline/reduced graphene oxide as electrode material for supercapacitor," Chemical Engineering Journal, vol. 304, pp. 29-38, 2016.

[51] G. Ma, Z. Zhang, K. Sun et al., "High-performance aqueous asymmetric supercapacitor based on $\mathrm{K}_{0.3} \mathrm{WO}_{3}$ nanorods and nitrogen-doped porous carbon," Journal of Power Sources, vol. 330, pp. 219-230, 2016. 


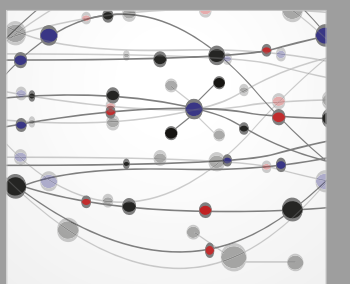

The Scientific World Journal
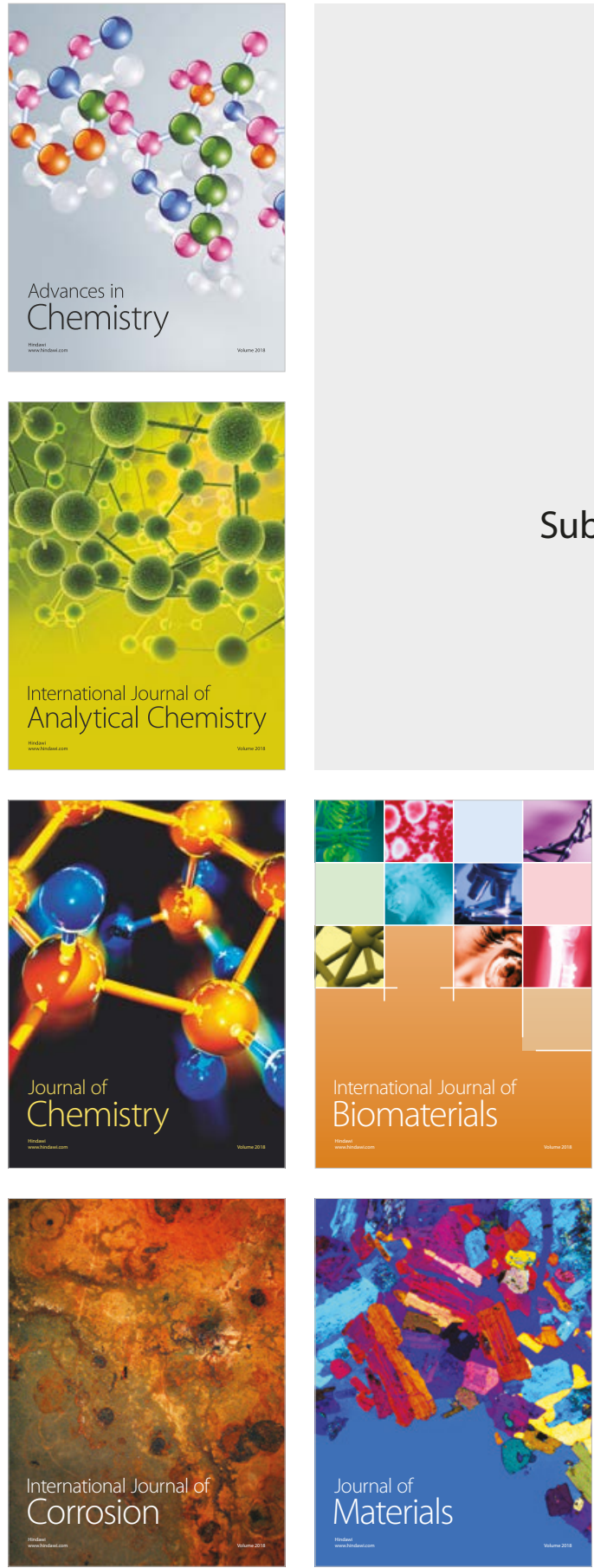

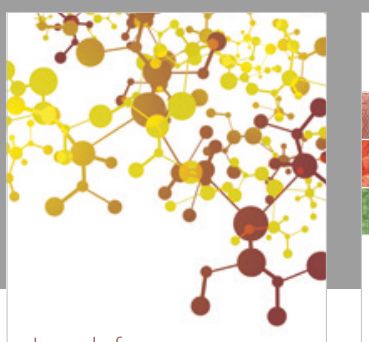

Journal of

Applied Chemistry
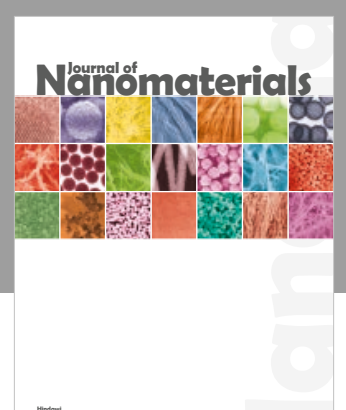

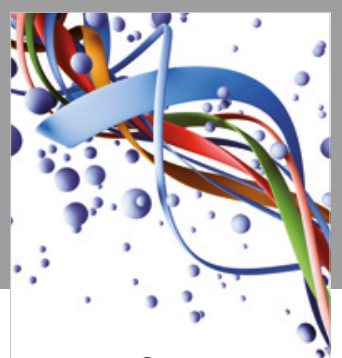

Scientifica

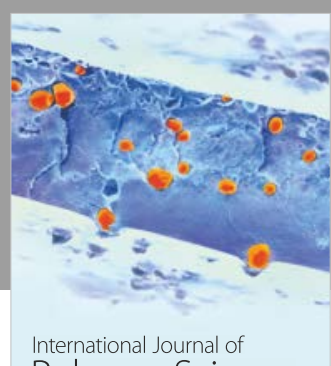

Polymer Science

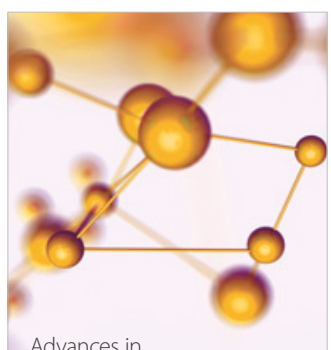

Physical Chemistry
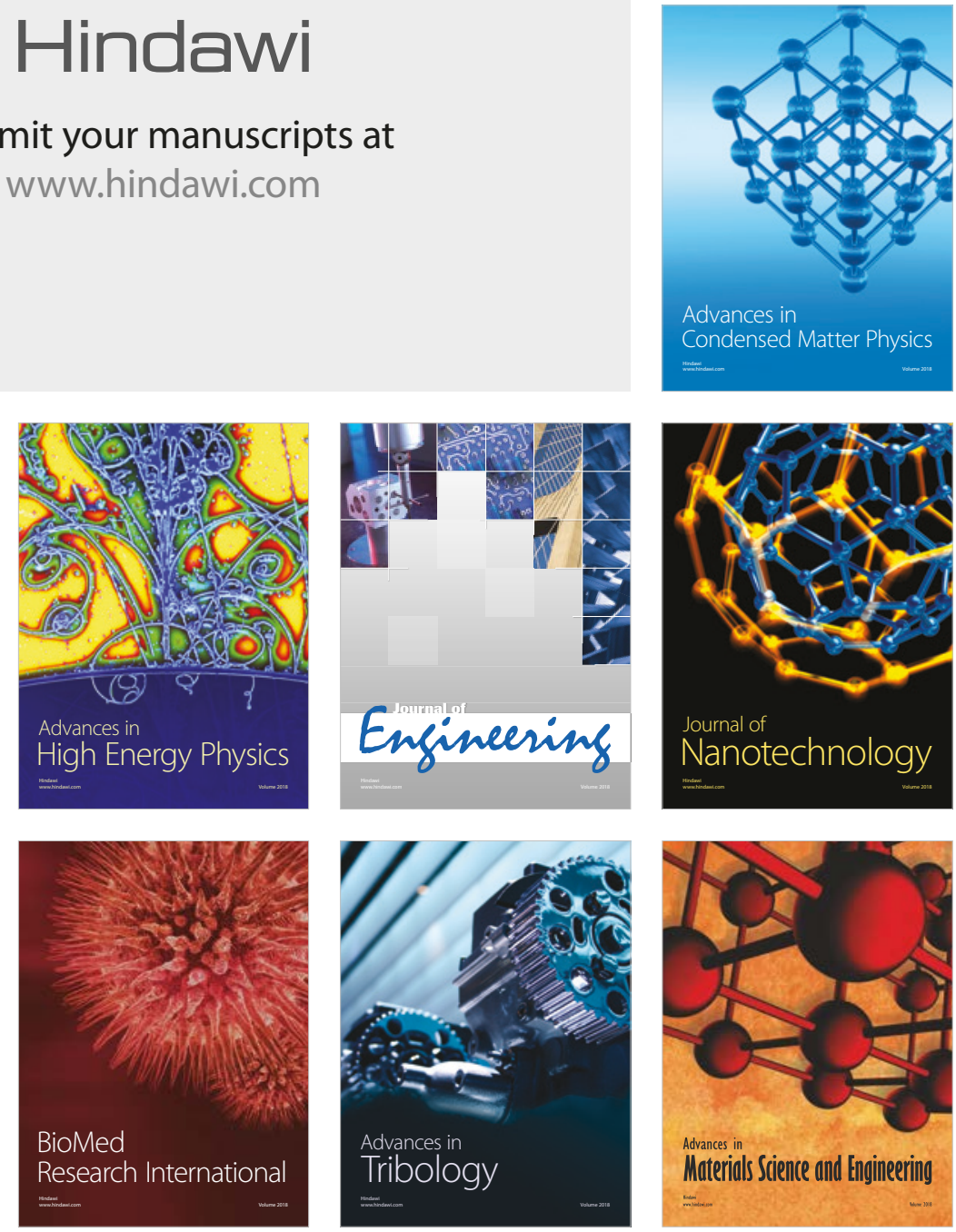